\title{
Regional difference of sea surface salinity variations in the western tropical pacific
}

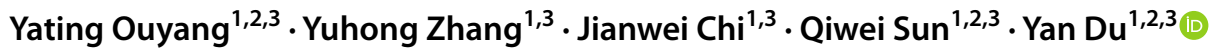

Received: 24 October 2020 / Revised: 22 January 2021 / Accepted: 16 February 2021 / Published online: 27 February 2021

(c) The Author(s) 2021

\begin{abstract}
Regional difference of sea surface salinity (SSS) variations in the western tropical Pacific is investigated with Ocean Reanalysis System 5 datasets. Three robust zonal bands of SSS variations have been identified in the northwestern tropical Pacific (NWTP), the western equatorial tropical Pacific (WEqP), and the southwestern tropical Pacific (SWTP), respectively. SSS in the WEqP and the SWTP has a strong interannual variability that is related to ENSO. In the WEqP, SSS variations are mainly controlled by anomalous freshwater flux, while in the SWTP they are governed by both freshwater forcing and oceanic processes. In the NWTP, SSS variations present a low-frequency variability that is correlated with Interdecadal Pacific Oscillation (IPO), which is mostly dominated by the freshwater flux and strongly adjusted by the ocean advection and mixed layer changes. After removing interannual signals, the SSS in all three regions are highly related to IPO, indicating that IPO has a general influence on the western tropical Pacific.
\end{abstract}

Keywords Sea surface salinity · Western tropical Pacific · Interannual variability · El Niño Southern Oscillation · Interdecadal Pacific Oscillation

\section{Introduction}

Sea surface salinity (SSS) is a primary indicator of the hydrological cycle and air-sea interaction (Durack and Wijffels 2010; Hasegawa et al. 2013). Understanding of the relationship between SSS and the relevant atmosphereoceanic processes could improve the climate model simulation and prediction (Durack et al. 2012). Significant seasonal and interannual SSS variations have been found in the western tropical Pacific based on the in situ observations

Yuhong Zhang

zhangyuhong@scsio.ac.cn

Yan Du

duyan@scsio.ac.cn

1 State Key Laboratory of Tropical Oceanography, South China Sea Institute of Oceanology \& Innovation Academy of South China Sea Ecology and Environmental Engineering, Chinese Academy of Sciences, Guangzhou, China

2 College of Marine Science, University of Chinese Academy of Sciences, Beijing, China

3 Southern Marine Science and Engineering Guangdong Laboratory, Guangzhou, China from mooring buoys or cruise's CTD measurements, which started from the mid-twentieth century. As the satellite remote sensing measurements and the array for real-time geostrophic oceanography (Argo) observations have been developed, more ocean salinity data have been obtained, leading to further investigations on the long-term trend and interdecadal variability of SSS in the western tropical Pacific.

Interannual variabilities in SSS are mainly driven by freshwater forcing that related to El Niño-Southern Oscillation (ENSO) associated processes in the western Pacific fresh pool, equatorial Pacific cold tongue, the Intertropical Convergence Zone (ITCZ), and the South Pacific convergence zone (Delcroix and Hénin 1991; Delcroix et al. 1996; Maes 2000; Zhao et al. 2016; Zheng and Zhang 2012). When sea surface temperature (SST) is abnormal warmer or cooler than usual status in central and eastern tropical Pacific, the ascending branch of Walker circulation moves eastward or westward, which cause a negative or positive precipitation anomaly in the western tropical Pacific thus increase or decrease the SSS (Bjerknes 1969; Dai and Wigley 2000). Apart from the freshwater forcing, SSS variations in the tropical Pacific can be attributed to zonal transport anomalies (Cronin and McPhaden 1998) and meridional 
transport anomalies (Chi et al. 2019; Qu et al. 2009) during an ENSO event.

A long-term freshening trend of SSS exists in the western tropical Pacific. Under global warming, the enhanced global hydrological cycle leads to more precipitation in the regions of heavy rainfall, such as the western tropical Pacific, which is called the "wet get wetter" theory (Boyer et al. 2005; Chou et al. 2009; Cravatte et al. 2009; Durack and Wijffels 2010; Durack et al. 2012; Hosoda et al. 2009). However, in contrast to the long-term freshening trend, a saline trend of the upper ocean salinity in the western tropical Pacific was identified from the mid-1990s to 2014 (Du et al. 2015), which coincided with the period of global warming hiatus (Meehl et al. 2011). Soon after 2015, the SSS in the northern tropical Pacific and the SPCZ starts decreasing again (Shi et al. 2020). The SSS tendencies occurred in the past few decades suggest that there is a significant interdecadal variability overlapping on the monotonic freshening trend associated with global warming. The SSS variations induced by interdecadal variabilities such as the Pacific Decadal Oscillation (PDO) and the Interdecadal Pacific Oscillation (IPO) have been identified in the tropical and northwestern Pacific ( $\mathrm{Hu}$ et al. 2020; Yan et al. 2017, 2019). Low-frequency oscillations like PDO and IPO can influence upper ocean salinity by changing the rainfall pattern in the tropical Pacific and the tropical-subtropical water transport in the Pacific circulation system (Du et al. 2015, 2019; Li et al. 2019; Zhang and Qu 2014).

The interannual and interdecadal variabilities of SSS associated with the ENSO and the IPO have been well investigated in the basin scale, but few studies focused on the regional difference in the western tropical Pacific. In this work, we show that there are three robust SSS variation regions in the western tropical Pacific: the northwestern tropical Pacific (NWTP), the western equatorial Pacific (WEqP), and the southwestern tropical Pacific (SWTP) (Fig. 1). We investigate the factors that influence the SSS changes in the three regions using Ocean Re-Analysis System5 (ORAS5) datasets (Zuo et al. 2019) from 1979-2017, and discussed the difference and resemblance among the three regions and the relationship with major climate modes in the tropical Pacific.

The datasets and methods are introduced in "Data and method". In "Results", the different variations of SSS among these three regions and associated processes including freshwater forcing and advection are examined. We also discuss the uniform interdecadal variability over the three regions in "Results". The conclusions and discussion are given in "Summary and discussion".

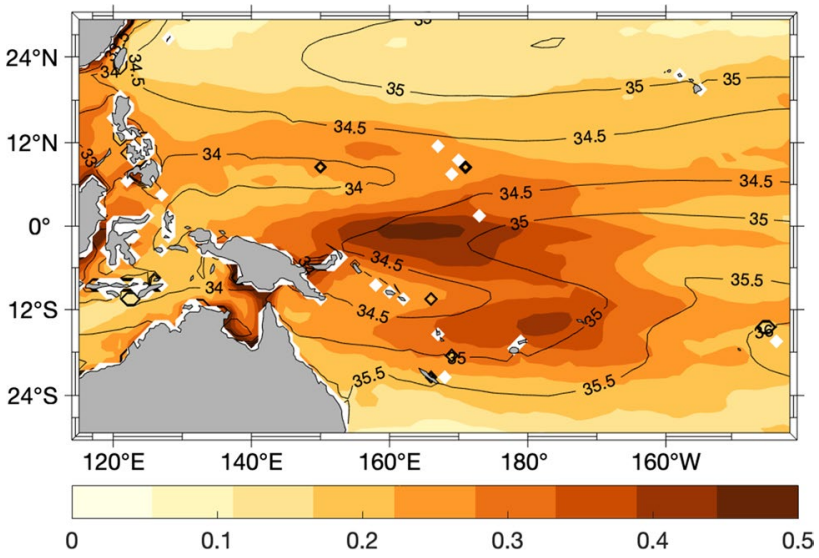

Fig. 1 Root mean square of SSS in the western tropical Pacific during 1979-2017, superimposed with SSS climatology. The seasonal cycle was removed

\section{Data and method}

\subsection{Data}

ORAS5 product from the European Centre for MediumRange Weather Forecasts (ECMWF) was used to examine the variation of SSS, and explain the related ocean-atmosphere processes in the western tropical Pacific. ORAS5 is based on the Nucleus for European Modelling of the Ocean (NEMO), perturbing by both observations and forcing fields. Its forcing fields are from ECMWF Re-Analysis ERA30 before 1979, ERA-Interim from 1979 to 2014, and ECMWF OPS after 2015. The assimilated observations include SST from Hadley Centre before 2007 and Operational Sea Surface Temperature and Sea Ice Analysis (OSTIA) after 2008, sea ice concentration from ERA before 1981, Reynolds from 1981 to 1984, OSTIA reprocessed from 1985 to 2007, and OSTIA analysis after 2008, SSS from EN4 before 2015 and Global Telecommunication System (GTS) after 2015, and SSH from Archiving Validation and Interpretation of Satellite Oceanographic data (AVISO) since 1993. The reanalysis products are provided in monthly data from 1979 to present with $1^{\circ} \times 1^{\circ}$ resolution (Zuo et al. 2019). Mixed layer depth (MLD) is calculated from density based on a temperature criterion of a $0.2{ }^{\circ} \mathrm{C}$ decrease from the SST (Kara et al. 2000). Because this dataset does not provide vertical velocity, we estimated the vertical process with the change of MLD. As the vertical mixing increases, the depth of mixed layer increases as well (Garwood et al. 1985).

Monthly precipitation rates are from the Global Precipitation Climatology Project (GPCP) version 2.3 from 1979 to 2018 with $2.5^{\circ} \times 2.5^{\circ}$ resolution (Adler et al. 2018). Monthly evaporation rates from Objectively Analyzed 
Air-Sea Fluxes (OAFlux) are provided by Woods Hole Oceanographic Institution since 1958 with $1^{\circ} \times 1^{\circ}$ resolution. OAFlux evaporation was calculated from multi-satellite sensors and observational platforms ( $\mathrm{Yu}$ and Weller 2007). We use evaporation minus precipitation (E-P) to represent total freshwater exchange between the atmosphere and the ocean.

Niño3.4 index and Tripole Pacific index (TPI) are both calculated from the Hadley Centre SST dataset (HadISST1). Niño3.4 index is the mean SST anomaly at the central equatorial Pacific $\left(170^{\circ} \mathrm{E}-120^{\circ} \mathrm{W}, 5^{\circ} \mathrm{S}-5^{\circ} \mathrm{N}\right)$. TPI is the mean difference from central tropical Pacific $\left(170^{\circ} \mathrm{E}-90^{\circ} \mathrm{W}, 10^{\circ} \mathrm{S}-10^{\circ} \mathrm{N}\right)$ SST anomaly to southwestern Pacific $\left(150^{\circ} \mathrm{E}-160^{\circ} \mathrm{W}\right.$, $\left.50^{\circ}-15^{\circ} \mathrm{S}\right)$ and northwestern Pacific $\left(140^{\circ} \mathrm{E}-145^{\circ} \mathrm{W}\right.$, $25^{\circ}-45^{\circ} \mathrm{N}$ ) SST anomaly (Henley et al. 2015). The IPO is a decadal-to-interdecadal climate variability in the entire Pacific Ocean basin, while its North Pacific node can be regarded as PDO. The method of TPI includes the signals that exist at the equator and mid-latitude basin, therefore it can portrait the IPO.

\subsection{Method}

The Empirical Orthogonal Function (EOF) analysis (Lorenz 1956) was used to examine the space-time variations of SSS, freshwater forcing, sea surface currents, and mixed layer depth anomalies. This method separates the main feature vectors from the data matrix that describes the orthogonal signals in the three-dimensional data.

The equation used to calculate salinity budget is taken as follow (Feng et al. 1998):

$\frac{\partial \mathrm{S}}{\partial t}=-\left(u \frac{\partial S}{\partial x}+v \frac{\partial S}{\partial y}\right)-S_{0} \frac{(P-E)}{h}-w_{e} \frac{S-S_{-h}}{h}$

where $S, S_{0}, S_{-h}$ are the mixed layer salinity, SSS, and the salinity at the bottom of the mixed layer, respectively. $u, v$ and $w_{e}$ denote zonal, meridional, and vertical entrainment component of velocity, respectively. $P$ and $E E$ represent precipitation and evaporation. The left-hand side of (1) is the mixed layer salinity tendency. The first to third terms in the right-hand side of (1) are the contributions of horizontal advection, freshwater flux, and vertical entrainment, respectively. The salinity budget analysis conducted in this study was focused on the contributions made by horizontal advection and freshwater flux to the SSS changes. All seasonal cycles were removed by subtracting the climatological monthly mean.

\section{Results}

\subsection{Regional difference of SSS in the western tropical Pacific}

Previous studies that focused on different time scales of salinity variability in the western tropical Pacific show few variation centers. For interannual variability, the western equatorial Pacific presents the largest SSS anomaly (Delcroix et al. 1996; Hasson et al. 2013; Zheng and Zhang 2015). For interdecadal variability, off-equatorial western Pacific show the most significant signals (Du et al. 2015; Durack and Wijffels 2010; Nan et al. 2015; Yan et al. 2019). Three SSS maximum variation regions can be found during $1979-2017$, the NWTP $\left(125^{\circ} \mathrm{E}-140^{\circ} \mathrm{W}\right.$, $\left.5^{\circ} \mathrm{N}-30^{\circ} \mathrm{N}\right)$, the $\mathrm{WEqP}\left(140^{\circ} \mathrm{E}-140^{\circ} \mathrm{W}, 5^{\circ} \mathrm{N}-10^{\circ} \mathrm{S}\right)$, and the SWTP $\left(140^{\circ} \mathrm{E}-140^{\circ} \mathrm{W}, 10^{\circ}-30^{\circ} \mathrm{S}\right)$, respectively (Fig. 1). The RMS maxima suggest that there are different variabilities and forcing existing in each region.

To portrait the SSS variations in each region, EOF analysis was applied to SSS in three different domains. The first EOF modes (EOF1) explain 33.8, 43.0, and 31.0\% of the total SSS variances in the NWTP, WEqP, and SWTP, respectively (Fig. 2). The EOF1 of SSS in each region has a similar spatial distribution as the RMS maximum, indicating that the EOF1s capture the main feature of SSS variability. The EOF1s of SSS in the WEqP and the SWTP show a pair of dipole-like structure, which is negative in the equator and positive in the south during the positive phase of ENSO. SSS variability in the western tropical Pacific is known to be highly correlated with the ENSO cycle (Maes 2000; Wang and Chao 2004). In the WEqP and SWTP, the correlation coefficients between the first principal component (PC1) of SSS and Niño3.4 index both exceed 0.7 with the time lags of 1 and 5 months, respectively (Table 1), indicating that the SSS variations are controlled by the atmospheric and oceanic forcing induced by ENSO. In the NWTP, the SSS variation does not in consonance with the other two regions, which barely correlate with ENSO, but highly correlated with IPO. The PC1 of SSS in the NWTP shows two contrasting phases, negative before the late 1990s and positive after (Fig. 2a, d). Those SSS variations coincide with the climate regime shift around 1998 (Bond et al. 2003), indicating an interdecadal variability. The IPO-related low-frequency SSS variability has comparable amplitude with the ENSO-related variations, albeit the absence of ENSO variability in the NWTP makes smaller RMS than the other two regions.

Prominent periods of SSS variations in three regions are shown in the power spectra of SSS PC1s within their domains (Figs. 3a-c). The WEqP and the SWTP feature with a 5.1-year period, consistent with the ENSO cycle (about 
(a)

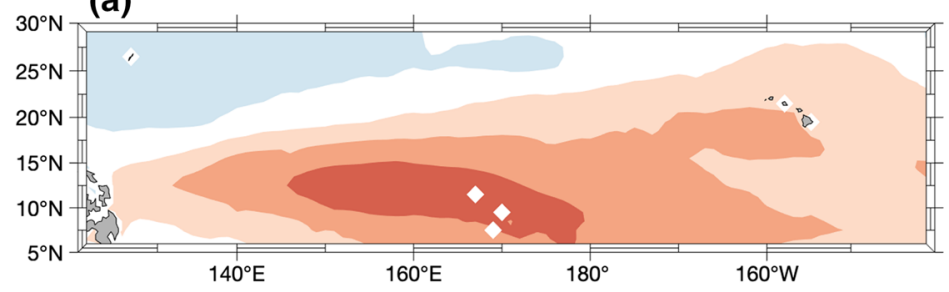

(b)

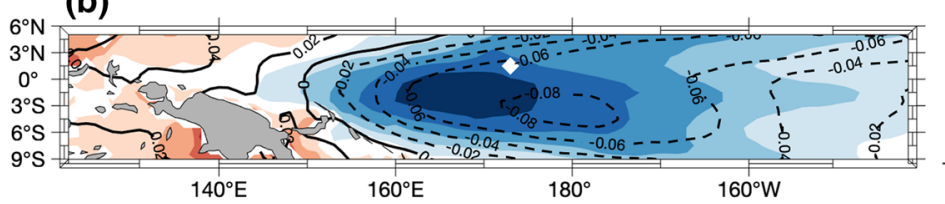

(c)

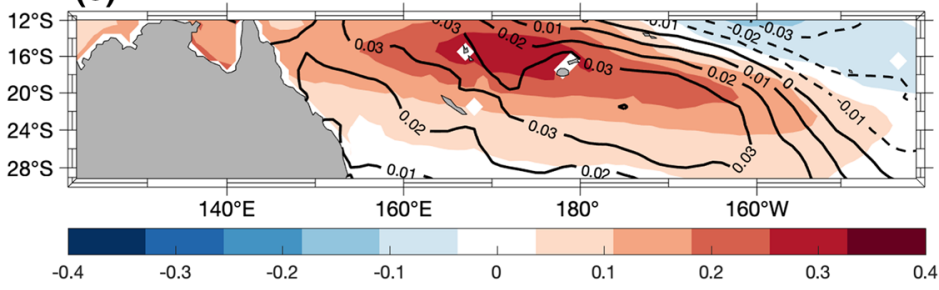

(d)

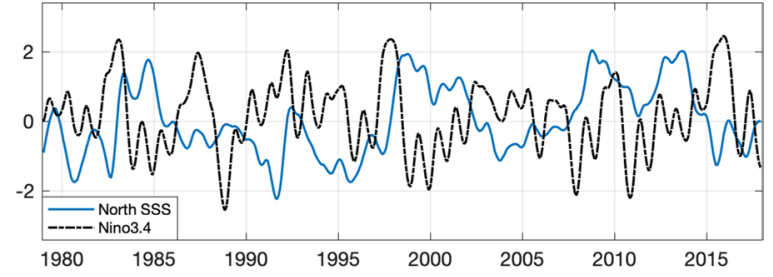

(e)

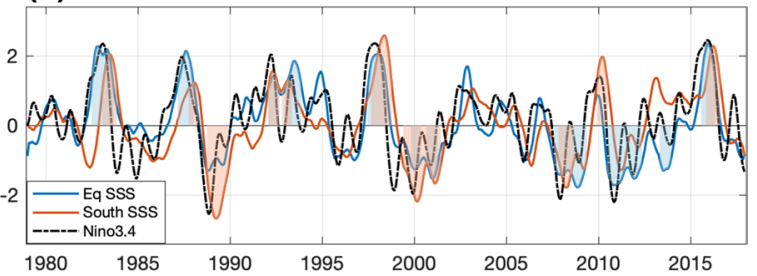

(f)

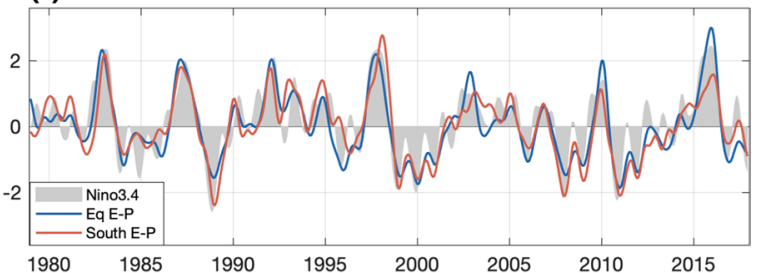

Fig. 2 The first EOF modes of SSS and E-P in the three regions of the western tropical Pacific. a SSS EOF1 in the NWTP, b SSS EOF1 in the WEqP (shaded), superimposed with E-P EOF1 (contour), c SSS EOF1 in the SWTP (shaded), superimposed with E-P EOF1 (contour), d SSS PC1 in the NWTP (blue line) and Niño3.4 index (black dotted line), e SSS PC1s in the WEqP (blue line) and the SWTP (orange line), and Niño3.4 index (black dotted line), SSS anomaly events (PC1 exceeds one standard deviation continuously over 3 months) are filled with blue and orange in the equator and the south, f E-P PC1s in the WEqP (blue line) and the SWTP (orange line), and Niño3.4 index is filled with gray. All seasonal cycles were removed
Table 1 The lead-lag correlations in the NWTP, the WEqP, and the SWTP

\begin{tabular}{|c|c|c|c|c|}
\hline \multirow[t]{2}{*}{ North } & $\begin{array}{l}\text { TPI-SSS PC1 } \\
\text { (5 yr lowpass) }\end{array}$ & $\begin{array}{l}\text { E-P PC1-SSS PC1 } \\
\text { (5 yr lowpass) }\end{array}$ & $\begin{array}{l}\text { Sea Surface Current } \\
\text { PC1-SSS PC1 } \\
\text { (5 yr lowpass) }\end{array}$ & $\begin{array}{l}\text { MLD PC1-SSS PC1 } \\
\text { (5 yr lowpass) }\end{array}$ \\
\hline & $R=-0.78(-1)$ & $R=0.88(12)$ & $R=0.77(7)$ & $R=0.83(6)$ \\
\hline \multirow[t]{2}{*}{ Equator } & Niño3.4-SSS PC1 & Niño3.4-E-P PC1 & E-P PC1-SSS PC1 & \\
\hline & $R=0.72(1)$ & $R=0.80$ & $R=0.87(1)$ & \\
\hline \multirow[t]{2}{*}{ South } & Niño3.4-SSS PC1 & Niño3.4-E-P PC1 & E-P PC1-SSS PC1 & \\
\hline & $R=0.73(5)$ & $R=0.73(1)$ & $R=0.79(4)$ & \\
\hline
\end{tabular}

$R$ represents the correlation coefficient between the two variables above it. The parenthesis behind $R$ represents the leading month(s) of the former variable 4.5-year period). A weaker variation around 2-year period also exists in the WEqP and the SWTP, which is associated with the biennial oscillation in the tropical Pacific troposphere (Li et al. 2006) and basin-scale response in the Indian Ocean (Xie et al. 2009). The most significant period of SSS variation in the NWTP is 12.7 years. SSS PC1 in the NWTP have a contemporaneous high correlation with TPI (Table 1), implying the IPO is the leading mode in the low-frequency variability of SSS. However, the longer period of IPO (over 20 years) is not shown in the spectrum, because it can hardly be captured in a 39-year data span. It notes that the power spectra of SSS PC1s in the WEqP and the SWTP exhibit a relatively high variance around 12.7 -year period (Figs. 3b, c), but does not pass the significant test, which is probably due to the strong interannual variability obscuring the lowfrequency signal. We apply a 5-year lowpass filter to separate low-frequency variability in the regions. After lowpass filtering, SSS PC1s in the three regions present almost identical variability that is associated well with the TPI (Fig. 3d), indicating that the uniform low-frequency variation of SSS is influenced by the low-frequency variability of IPO in the entire western tropical Pacific during the past few decades. 
(a)

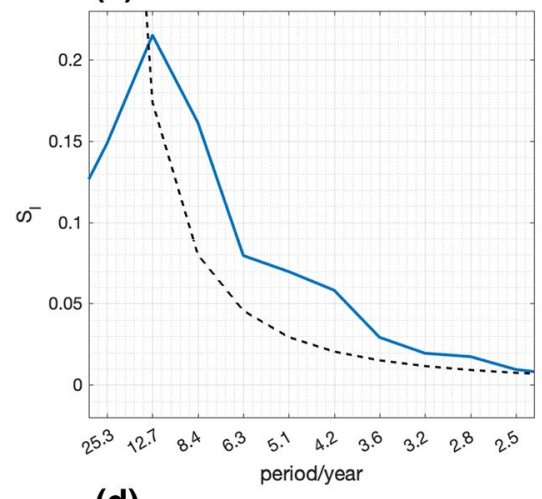

(b)

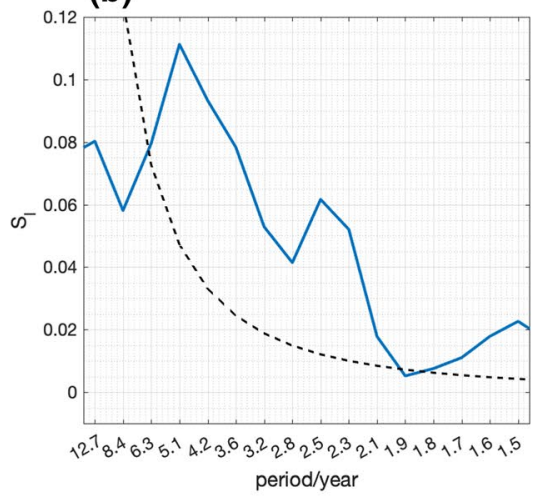

(c)

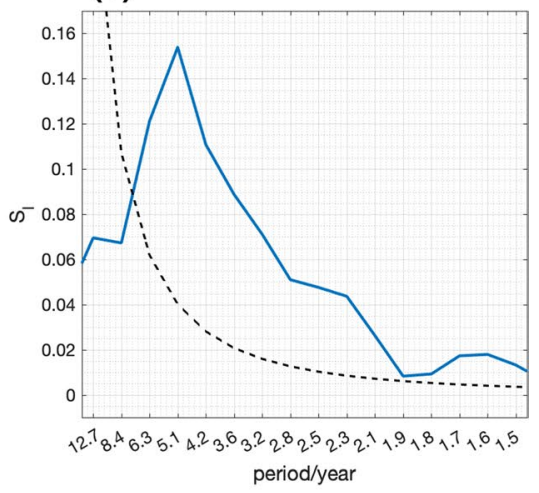

(d)

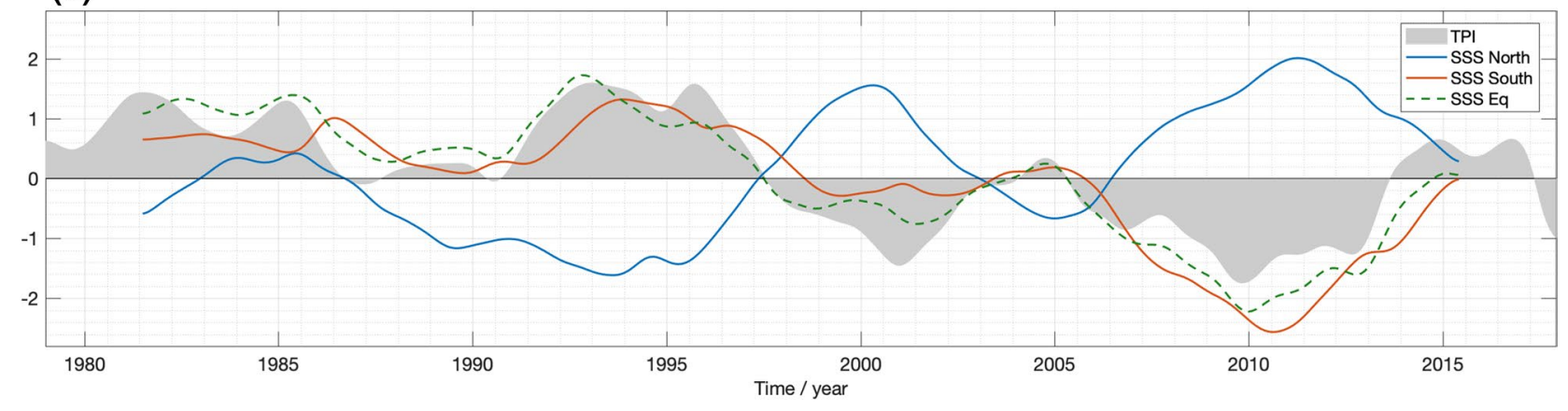

Fig. 3 The power spectra of SSS PC1s in the western tropical Pacific: a the NWTP, $\mathbf{b}$ the WEqP, and $\mathbf{c}$ the SWTP, with the blue lines represent the power spectrum, and the black dotted line lines represent 95\% confidence level. d PC1s of SSS filtered by a 5-year lowpass fil- ter in the north (blue solid line), the equator (orange solid line), and the south (orange dotted line), the IPO index (TPI) is filtered by a 5-year lowpass filter and filled with gray

\subsection{Interannual variations in the WEqP and the SWTP}

The spatial patterns of E-P and SSS variation are similar in the WEqP and SWTP (Figs. 2b, c), where the freshwater flux has a high correlation with the ENSO cycle. The increase of SSS in the western tropical Pacific is often concurred with the decrease of rainfall, especially during an El Niño event when the ascending branch of Walker Circulation shifts eastward (Delcroix et al. 1996; Ioualalen and Henin 2001). In regions with intense rainfall variations, the change of SSS occurs approximately 2-3 months after freshwater forcing according to empirical time-lag correlation analyses (Delcroix et al. 1996).

We define the anomalous interannual SSS event in the WEqP and the SWTP as SSS PC1 exceeds one standard deviation continuously over 3 months (Fig. 2e). According to the lead-lag relation between freshwater flux and SSS (Table 1), the composite of the forcing terms, including freshwater flux and horizontal advection, leads the corresponding SSS anomaly event 1 and 3 months in the WEqP and the SWTP, respectively. The composited SSS, freshwater flux, and horizontal advection anomalies in the WEqP are shown in Fig. 4. The maximum SSS anomaly in the $\mathrm{WEqP}$ is located at $170^{\circ} \mathrm{E}$ of the equator, which occurs 2 months after the mature phase of an El Niño event. The spatial structure of composited freshwater flux anomaly is very similar to the SSS in the middle of the WEqP $\left(150^{\circ} \mathrm{E}-150^{\circ} \mathrm{W}, 9^{\circ} \mathrm{S}-6^{\circ} \mathrm{N}\right)$, while the composited horizontal advection anomaly is consistent with SSS anomaly in the western marginal sea of the equatorial Pacific where freshwater flux cannot explain SSS changes. Freshwater flux anomaly presents no robust variance in the western coastal region during both positive and negative SSS anomaly periods. While during the positive SSS anomaly periods, freshwater flux anomaly is stronger than expected in the east of $160^{\circ} \mathrm{W}$. Horizontal advection anomaly contrasts with SSS changes in the equator, which have been mostly offset by intense freshwater forcing. The spatial ranges of negative SSS anomaly and the corresponding freshwater flux anomaly are wider than that of their positive phase in the WEqP. Together with the expanded negative anomaly range, the anomaly pattern of SSS, freshwater flux, and horizontal advection shift eastward. The eastward shift of negative SSS reflects the asymmetry of ENSO (An and Jin 2004), suggesting that the SSS variations in WEqP are largely controlled by the ENSO-induced freshwater flux changes and wind-driven current anomaly. 
(a)

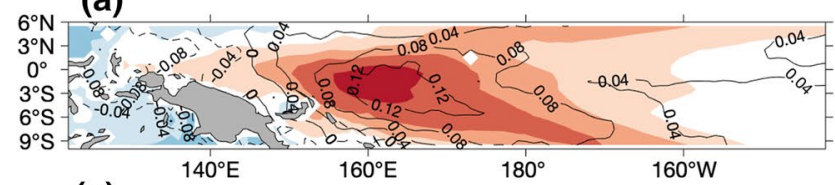

(c)

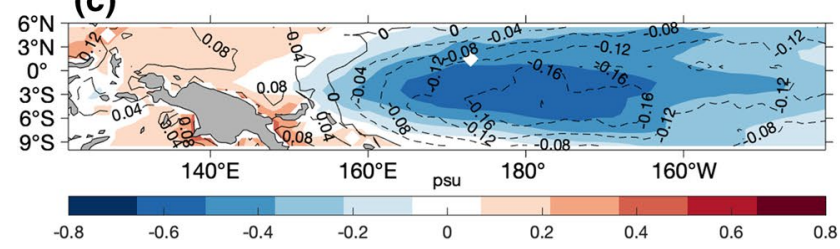

Fig. 4 The composites of anomalous fields during positive and negative SSS events in the WEqP: SSS anomaly (shaded, psu) superimposed with freshwater flux anomaly (contour, psu/month) in a positive event and c negative event, horizontal advection anomaly (shaded, psu/month) in $\mathbf{b}$ positive event and $\mathbf{d}$ negative event. Inter-

The SSS anomaly field in the south extends from the northwest to the southeast, centers at $160^{\circ} \mathrm{E}-180^{\circ}$, which also has a wider range in the negative phase comparing to the positive phase (Fig. 5c). The freshwater flux anomaly pattern is in good agreement with the SSS anomaly pattern in the SWTP, but they are not strictly coincided. Meanwhile, horizontal advection bears more resemblance to SSS in this area (Figs. 5b, d), indicating that advection directly affects SSS anomaly pattern in the south. Both freshwater forcing and oceanic processes are conducive to the SSS anomalies in the SWTP, showing that these factors have comparable impact on the changes of SSS in this area. The heavy and scattered rainfall caused by deep convection in the WEqP and the SWTP tends to have an immediate influence on the SSS variation. Therefore, the longer response time from SSS to freshwater forcing in the SWTP (Table 1) also indicates stronger effect from oceanic processes comparing to the WEqP. Apart from the freshwater forcing and horizontal (b)

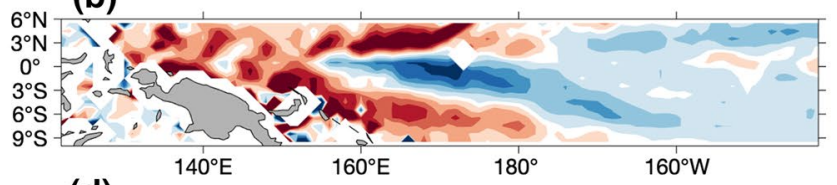

(d)

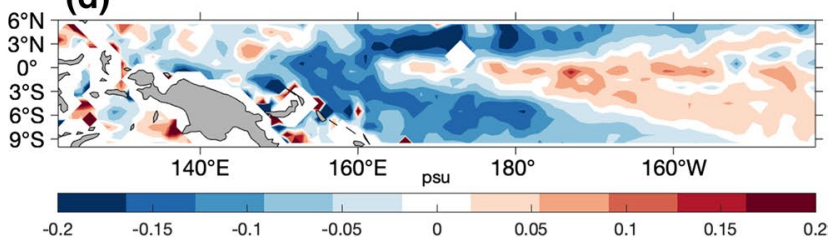

annual SSS anomaly events are defined as the values of SSS PC1 that exceeds one-time standard deviation continuously for at least 3 months. The anomalies of freshwater flux and horizontal advection lag the SSS anomaly for 1 month (equator) and 3 months (south). All seasonal cycles were removed

advection, the residual term also has a noticeable influence on SSS anomaly in certain areas. For example, in the northeastern part of the SWTP $\left(180^{\circ}-160^{\circ} \mathrm{W}, 10^{\circ}-15^{\circ} \mathrm{S}\right)$, neither freshwater flux nor horizontal advection could explain the SSS anomaly well (Figs. 5a, c), suggesting that vertical entrainment play a more important role in this area (Chi et al. 2019). The major difference between the forcing terms of SSS changes in the WEqP and the SWTP is that salt advection has greater influence on SSS changes in the southern region than in the equatorial region.

\subsection{Interdecadal variations in the NWTP}

Since pronounced interdecadal variability of SSS exists in the NWTP, we use a 5-year lowpass filter to investigate the low-frequency processes. EOF analysis is applied to SSS, E-P, sea surface current, and MLD after the 5-year lowpass filter. The first EOF modes of E-P, sea surface current, and (a)

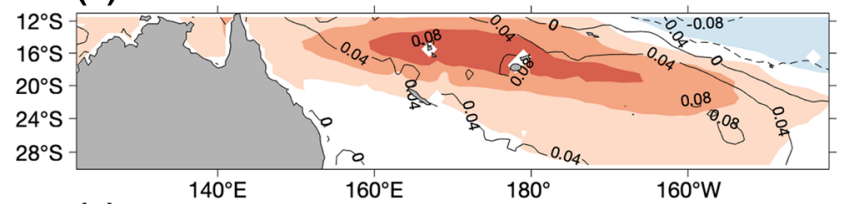

(c)

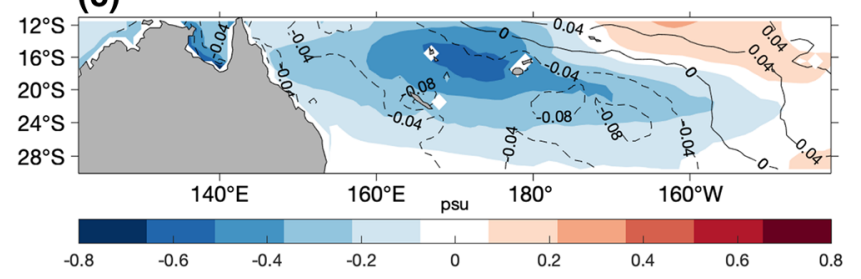

(b)

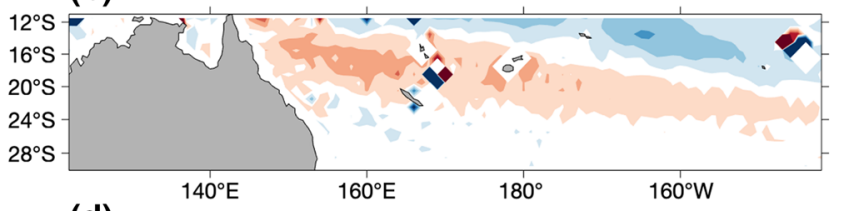

(d)

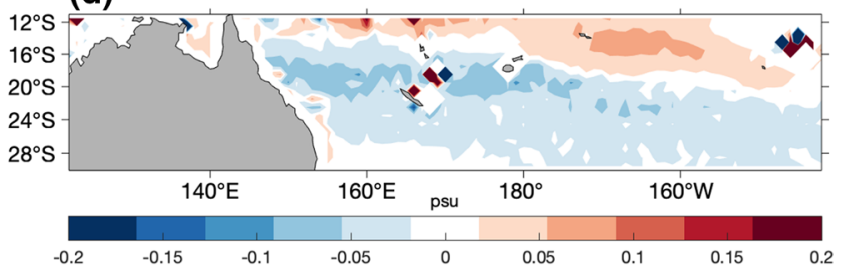

Fig. 5 The same variables as in Fig. 4, but in the SWTP: SSS anomaly (shaded, psu) superimposed with freshwater flux anomaly (contour, psu/ month) in a positive event and $\mathbf{c}$ negative event, horizontal advection anomaly (shaded, psu/month) in b positive event and $\mathbf{d}$ negative event 
MLD show high correlations with SSS in the spatial-temporal structure in the NWTP.

The EOF1 of filtered E-P shows a significant variation center $\left(160^{\circ} \mathrm{E}, 10^{\circ} \mathrm{N}\right)$ in the western part of the NWTP and a sharp decrease along latitude in the eastern part, which is similar to the pattern of SSS EOF1, with the centers of E-P anomaly slight in the south of the SSS anomaly (Fig. 6a). The PC1 of filtered SSS is highly related to that of the filtered E-P, with the largest correlation coefficient (0.88) appearing when the later leads for 12 months (Table 1). This indicates that the accumulated freshwater forcing has significant influence on SSS anomaly. However, the EOF1s of E-P and SSS bear no further resemblance outside the high variation regions where SSS still presents dramatic anomalies, suggesting that advection and mixing are also important in changing SSS outside of high E-P variation regions.

Sea surface current can modify the distribution of SSS. The northward advected upper current of the subtropical-tropical shallow overturning cell carries the tropical fresh surface water to the subtropical, balanced the regional salinity. The strengthening easterly (westerly) winds enhance (damp) the shallow overturning cell by increasing (decreasing) the divergence in the equator, and transport more (less) freshwater from equator to the north (Li et al. 2019), inducing significant SSS anomaly in the NWTP. Besides, the change of water advection by the North Equatorial Current contributes to the salinity variation in the NWTP (Du et al. 2015). The EOF1 of sea surface current shows a westward current anomaly south of $10^{\circ} \mathrm{N}$ and an eastward current anomaly of nearly $20^{\circ} \mathrm{N}$ during the positive phase (Fig. 7a), which is consistent with the result of the previous studies that the bifurcation of the North Equatorial Current moves southward in recent decades (Du et al. 2015; Qiu and Chen 2010; Gordon et al. 2014). These current anomalies favor the central high-salinity water advecting to the southwestern part of the NWTP and the western low-salinity water extending to the northwestern part of the NWTP (Figs. 1 and 8c). The center of subsurface high-salinity water in the north tropical Pacific locates in the southwest of the surface high-salinity water (Johnson et al. 2016). This indicates that the subsurface salinity is higher than SSS in the southwest of the north Pacific salinity maximum (about $25^{\circ} \mathrm{N}$ ). Enhanced mixing would introduce saltier subsurface water into the surface ocean, therefore increase the SSS. Model simulations suggested that the upper ocean mixing is important in keeping salinity balance in this region (Johnson et al. 2016). The EOF1 of MLD anomaly shows a similar variation range with the SSS EOF1 in the north, except that the maximum variation of MLD is $20^{\circ}$ longitude eastward to the SSS (Fig. 7a). The PC1 of SSS is significantly related to the PC1s of sea surface

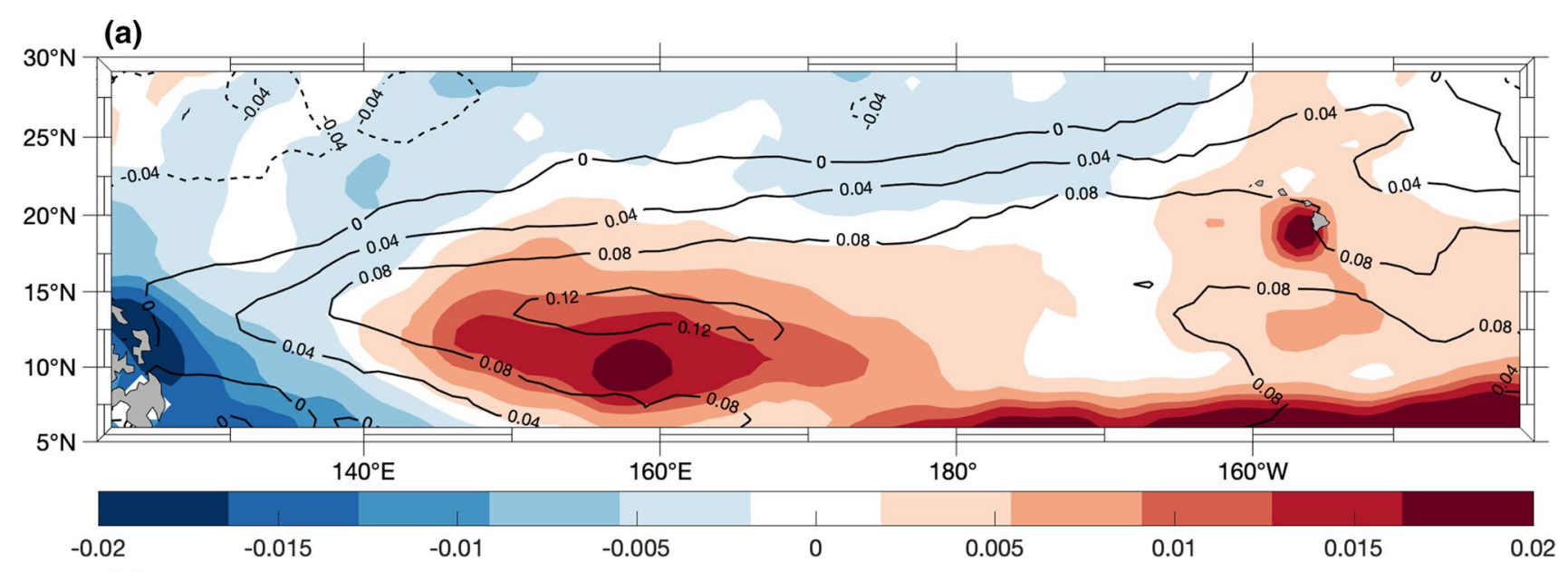

(b)

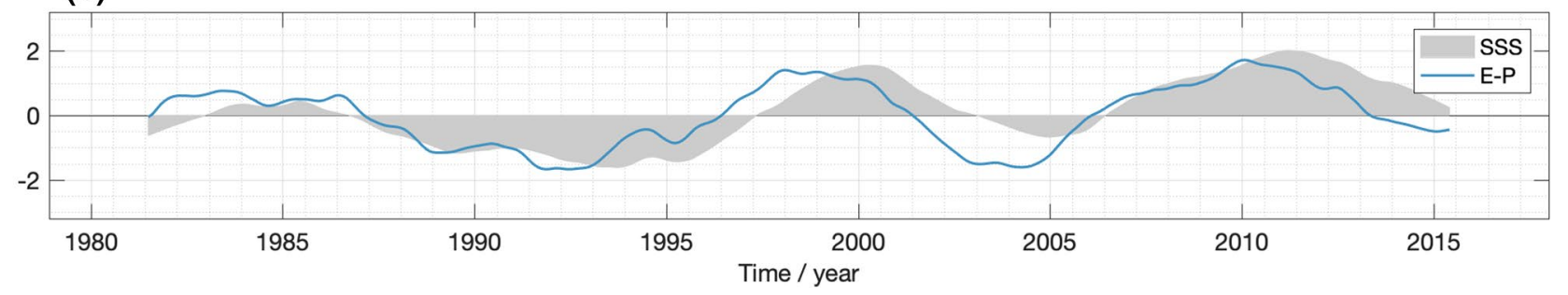

Fig. 6 The first EOF mode of 5-year lowpass filtered E-P and SSS in the northwestern tropical Pacific. a Filtered E-P EOF1 (shaded) superimposed with filtered SSS EOF1 (contour). b Filtered E-P PC1s (blue line) and filtered SSS PC1 filled with gray. The EOF analysis is applied to the filtered data of E-P and SSS. All seasonal cycles were removed 
(a)

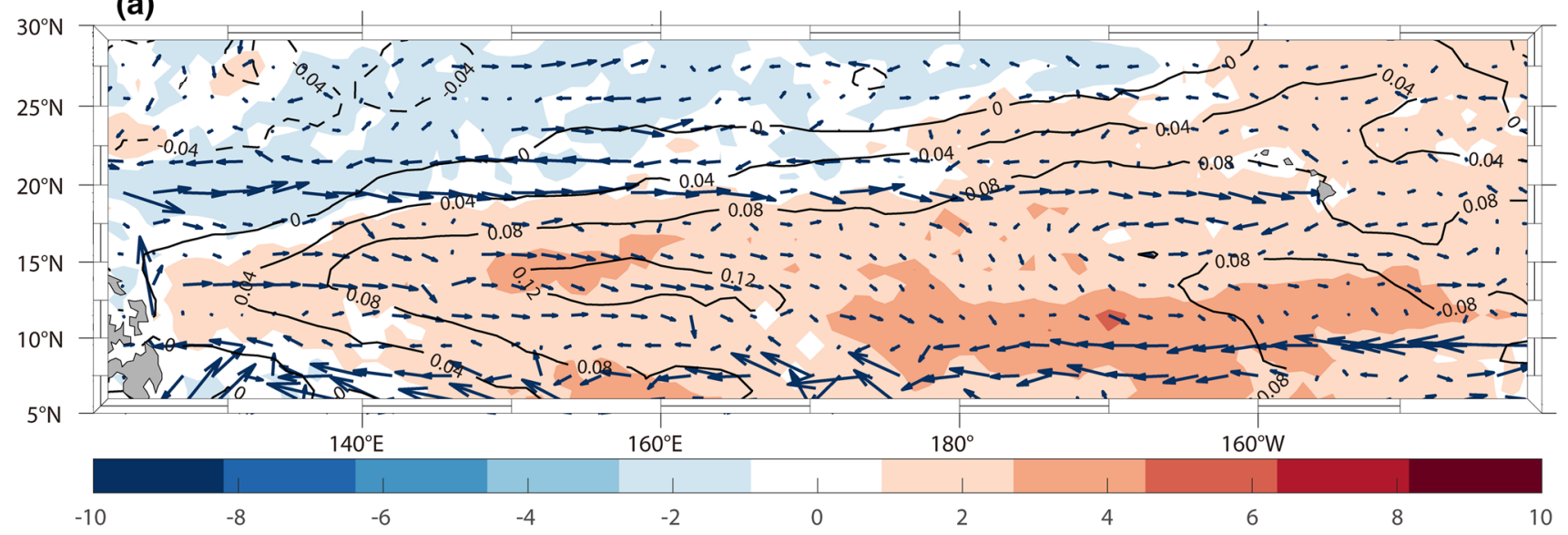

(b)

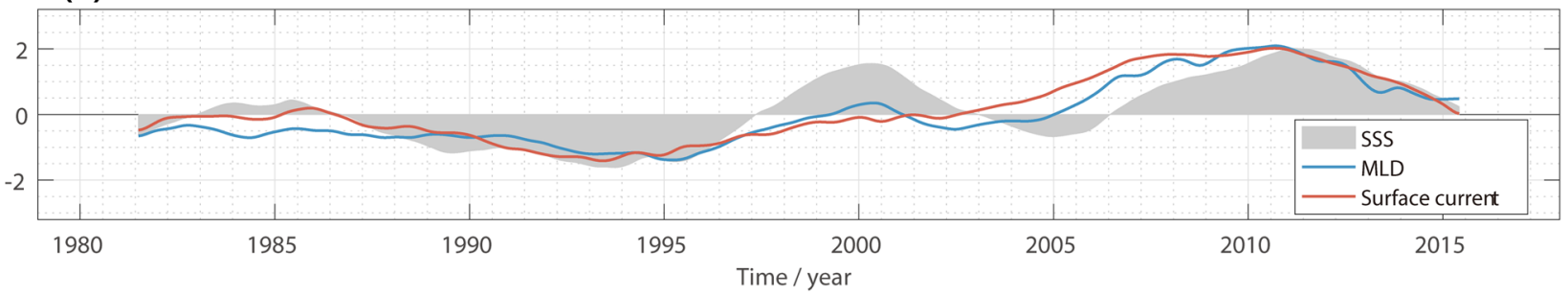

Fig. 7 The first EOF modes of 5-year lowpass filtered MLD, sea surface current, and SSS in the northwestern tropical Pacific. a EOF1s of MLD (shaded), sea surface current (vector), and SSS (contour). b PC1s of MLD (blue line), surface current (orange line), and SSS
PC1 is filled with gray. The EOF analysis is applied to the filtered data of MLD, sea surface current, and SSS. All seasonal cycles were removed current and MLD with a time lag of 6-7 months, showing that the response of salinity to dynamic processes is faster than E-P. The spatial pattern of SSS variation in the NWTP is determined by both freshwater flux and oceanic processes. Strong E-P anomalies determine the location of maximum SSS variation, and oceanic advection influences the areas where the E-P variation is not significant. The different roles of each forcing term also could be found in the temporal evolution. During the positive SSS anomaly period from 1997 to 2003, the contributions of advection and mixing are not significant, while E-P variations well explains the SSS changes (Figs. 6b and 7b).

We make composites of freshwater forcing and horizontal advection during the increasing and decreasing period of SSS PC1 to examine the effects of the forcing terms during positive and negative SSS anomaly periods in the NWTP. Figure 8 shows that the freshwater flux anomaly matches the SSS anomaly very well, suggesting that the strong freshwater forcing variation enhances the SSS anomaly greatly. Horizontal advection does not have a clear center, but it shows a similar variation range with SSS anomaly. The combination of freshwater flux and horizontal advection explains the major part of SSS anomalies.

\section{Summary and discussion}

This study uses the ORAS5 datasets to investigate the regional differences and connections among the three significant SSS variation regions during 1979-2017: the NWTP, the WEqP, and the SWTP. The EOF1s of SSS anomaly show different variabilities among the three regions. The contributions from the freshwater flux and oceanic advection are examined in each region.

Prominent interannual variability of SSS is found in the WEqP and the SWTP and interdecadal variability of SSS in the NWTP. In the WEqP, SSS variability is closely related to ENSO cycle, where the strong freshwater flux variations dominate the SSS changes. In the SWTP, both the E-P variation and horizontal advection dominate the SSS variations, also highly correlated with ENSO. In the NWTP, SSS anomaly varies with the low-frequency variations of the IPO, controlled by the combined effect of freshwater forcing and oceanic processes. The influence of horizontal advection cannot be ignored in both off-equatorial areas in the western Pacific (NWTP and SWTP), while its contribution is mostly offset by freshwater forcing in the WEqP. 


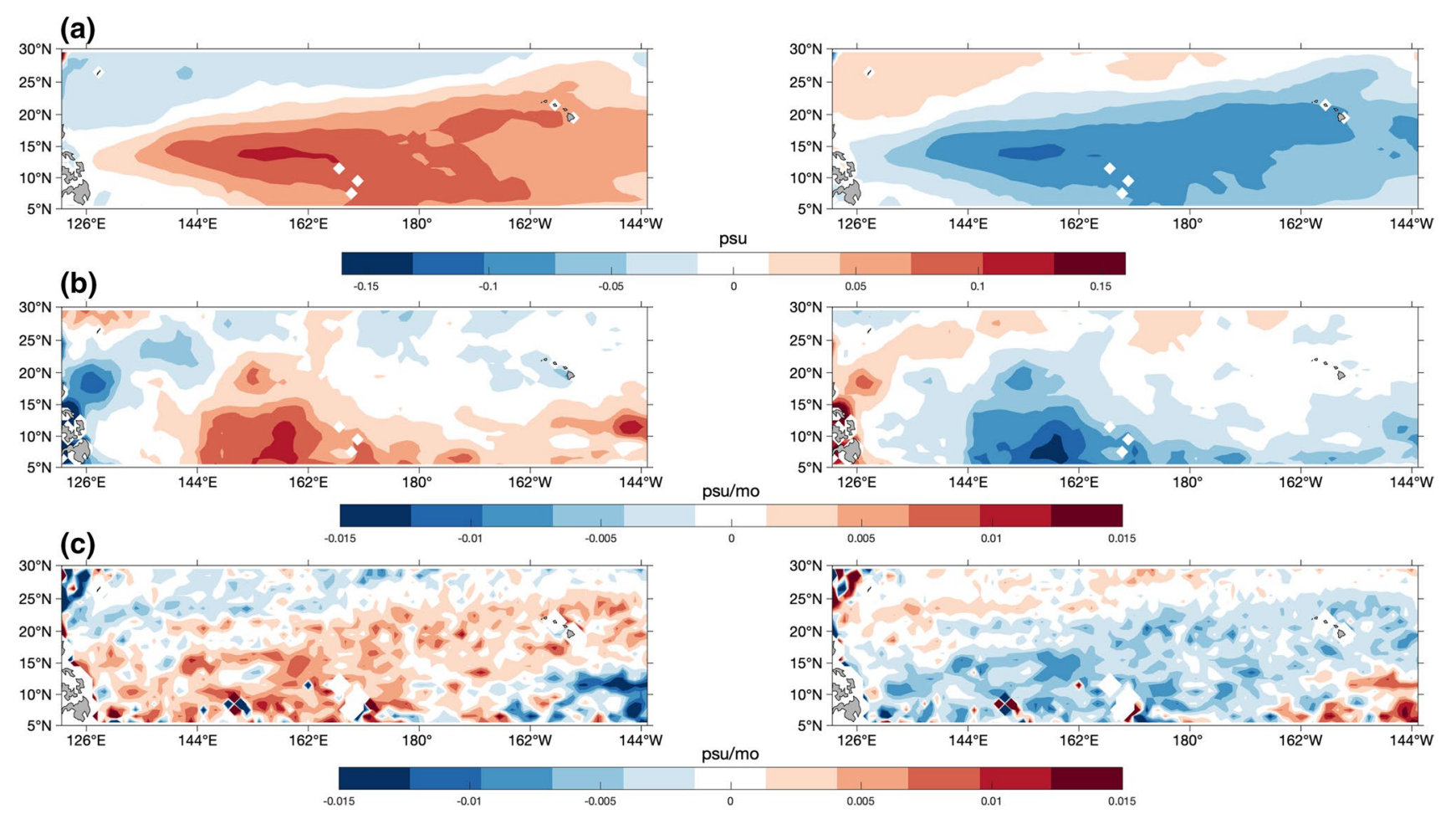

Fig. 8 Composites of anomalous fields during the positive and negative phase of 5-year lowpass filtered SSS anomaly in the northwestern tropical Pacific: a SSS anomaly (psu), b freshwater flux (psu/month), and $\mathbf{c}$ advection ( $\mathrm{psu} / \mathrm{month}$ ). The positive or negative composite of SSS is the mean SSS anomaly during its PC1 larger or smaller than

In this work, we find that the freshwater flux has significant influences on the SSS in all three regions, as an extension to some previous studies which focused on the effect of current advection in the upper ocean salinity variation (e.g., Cronin and McPhaden 1998). For example, Li et al. (2019) emphasized the role of anomalous currents which result in significant saltier or fresher water advection in the upper equatorial Indo-Pacific Ocean, while the effect of precipitation has been reduced. The impact of freshwater forcing on salinity changes is concentrated on the surface ocean, especially in the western tropical Pacific where the MLD is thin due to the fresh surface water. Different factors have various influences on SSS in different events (Zheng and Zhang 2012; Chi et al. 2019). The arguments about which factor is most important on the SSS variations reflect the fact that salinity variations in the tropical Pacific are complex either in temporal evolution or in spatial structure, which requires further investigations.

ORAS5 dataset is used to portrait the regional variation difference of SSS in this work, while a similar variation pattern of SSS is also found in Argo data and other reanalysis products such as Simple Ocean Data Assimilation (SODA). SSS observed by Argo floats are available after 2004, which shows the same variation pattern from 2004 zero. The composites of freshwater flux and horizontal advection are calculated on the positive or negative tendency of SSS PC1. SSS, freshwater flux, and horizontal advection are filtered before computing the composites fields

to 2018 as Fig. 1. The SSS variations of SODA3.3.1 in the western tropical Pacific are not consistent before and after 2004, which cannot be well explained by physical processes (figure not shown). The ORAS5 dataset has better performance in reconstructing SSS during the study period.

The lead-lag correlation analyses show that the SSS variation usually lags the freshwater forcing and oceanic advection (Table 1). Theoretically, SSS change should lag its tendency, the freshwater forcing, and the ocean advection terms in the budget equation for a quarter of the variation cycle. However, because of the errors from model data and observations, and the effect from the high-frequency disturbances, the time-lag of SSS to the forcing terms are not strictly a quarter cycle. This time-lag discrepancy is not considered in this study. The response time of SSS to the forcing terms varies with time scales and areas. For example, in the tropical Indian Ocean, the SSS variation lags current anomaly and E-P anomaly for 2 months on the interannual time scale (Zhang et al. 2016), and 2 3 years on the decadal time scale (Zhang et al. 2018). In the tropical Pacific Ocean, the interannual SSS variation lags the freshwater forcing and ocean dynamic processes for $2-4$ months (Gao et al. 2014), which is similar to the result of this study. As shown in Table 1, the interannual SSS variation in the WEqP responses the fastest 
to the freshwater forcing, followed by that in the SWTP, and finally the interdecadal SSS variation in the NWTP.

Recent researches based on the salinity observations and numerical models have improved our understandings of salinity influence on ENSO and improved the development of the numerical model prediction (Chi et al. 2019; Maes et al. 2005; Zheng and Zhang 2012; Zhu et al. 2014). The relationships between salinity variability in the upper Pacific Ocean and the interdecadal oscillations like IPO and PDO had been discussed (Du et al. 2015; Li et al. 2019; Yan et al. 2019). This work reveals the non-uniform structure of the SSS changes in the western tropical Pacific, identifies the major factors that influence the SSS variability and inspects the connections between these regions, which could help to understand the regional response to climate change in multi-time scales.

Acknowledgments We acknowledge the European Centre for MediumRange Weather Forecasts for hosting the Ocean Re-Analysis System 5 products (http://icdc.cen.uni-hamburg.de/thredds/catalog/ftpthredds /EASYInit/oras5/catalog.html). The HadISST1 was provided by the Met Office Hadley Centre (https://www.metoffice.gov.uk/hadobs/hadis st/). GPCP precipitation and evaporation were respectively obtained from the NASA/GSFC (http://precip.gsfc.nasa.gov) and OAFlux project (http://oaflux.whoi.edu/). The work at SCSIO/CAS is supported by the National Natural Science Foundation of China (41976024, and 42006028), the Chinese Academy of Sciences (XDB42010304, XDA15020901, 133244KYSB20190031), and the Southern Marine Science and Engineering Guangdong Laboratory (Guangzhou) (GML2019ZD0303, 2019BT02H594).

Open Access This article is licensed under a Creative Commons Attribution 4.0 International License, which permits use, sharing, adaptation, distribution and reproduction in any medium or format, as long as you give appropriate credit to the original author(s) and the source, provide a link to the Creative Commons licence, and indicate if changes were made. The images or other third party material in this article are included in the article's Creative Commons licence, unless indicated otherwise in a credit line to the material. If material is not included in the article's Creative Commons licence and your intended use is not permitted by statutory regulation or exceeds the permitted use, you will need to obtain permission directly from the copyright holder. To view a copy of this licence, visit http://creativecommons.org/licenses/by/4.0/.

\section{References}

Adler RF, Sapiano MRP, Huffman GJ, Wang JJ, Gu G, Bolvin D et al (2018) The global precipitation climatology project (GPCP) monthly analysis (new version 2.3) and a review of 2017 global precipitation. Atmosphere 9(4):138

An SI, Jin FF (2004) Nonlinearity and asymmetry of ENSO. J Clim 17(12):2399-2412

Bjerknes J (1969) Atmospheric teleconnections from equatorial Pacific. Mon Weather Rev 97(3):163-172

Bond NA, Overland JE, Spillane M, Stabeno P (2003) Recent shifts in the state of the North Pacific. Geophys Res Lett 30(23):4

Boyer TP, Levitus S, Antonov JI, Locarnini RA, Garcia HE (2005) Linear trends in salinity for the World Ocean, 1955-1998. Geophys Res Lett 32(1):4
Chi J, Du Y, Zhang Y, Nie X, Shi P, Qu T (2019) A new perspective of the 2014/15 failed El Nino as seen from ocean salinity. Sci Rep 9:8

Chou C, Neelin JD, Chen CA, Tu JY (2009) Evaluating the "rich-getricher" mechanism in tropical precipitation change under global warming. J Clim 22(8):1982-2005

Cravatte S, Delcroix T, Zhang D, McPhaden M, Leloup J (2009) Observed freshening and warming of the western Pacific Warm Pool. Clim Dyn 33(4):565-589

Cronin MF, McPhaden MJ (1998) Upper ocean salinity balance in the western equatorial Pacific. J Geophys Res Oceans 103(C12):27567-27587

Dai A, Wigley TML (2000) Global patterns of ENSO-induced precipitation. Geophys Res Lett 27(9):1283-1286

Delcroix T, Hénin C (1991) Seasonal and interannual variations of sea surface salinity in the tropical Pacific Ocean. J Geophys Res 96(C12):22135-22150

Delcroix T, Henin C, Porte V, Arkin P (1996) Precipitation and seasurface salinity in the tropical Pacific Ocean. Deep-Sea Res I 43(7):1123-1141

Du Y, Zhang Y, Feng M, Wang T, Zhang N, Wijffels S (2015) Decadal trends of the upper ocean salinity in the tropical Indo-Pacific since mid-1990s. Sci Rep 5:16050

Du Y, Zhang Y, Shi J (2019) Relationship between sea surface salinity and ocean circulation and climate change. Sci China Earth Sci 62(5):771-782

Durack PJ, Wijffels SE (2010) Fifty-year trends in global ocean salinities and their relationship to broad-scale warming. J Clim 23(16):4342-4362

Durack PJ, Wijffels SE, Matear RJ (2012) Ocean salinities reveal strong global water cycle intensification during 1950 to 2000. Science 336(6080):455-458

Feng M, Hacker P, Lukas R (1998) Upper ocean heat and salt balances in response to a westerly wind burst in the western equatorial Pacific during TOGA COARE. J Geophys Res Oceans 103(C5):10289-10311

Gao S, Qu T, Nie X (2014) Mixed layer salinity budget in the tropical Pacific Ocean estimated by a global GCM. J Geophys Res Oceans 119(12):8255-8270

Garwood RW, Gallacher PC, Muller P (1985) Wind direction and equilibrium mixed layer depth: general theory. J Phys Oceanogr 15(10):1325-1331

Gordon AL, Flament P, Villanoy C, Centurioni L (2014) The nascent Kuroshio of Lamon Bay. J Geophys Res Oceans 119:4251-4263

Hasegawa T, Ando K, Ueki I, Mizuno K, Hosoda S (2013) Upperocean salinity variability in the tropical pacific: case study for quasi-decadal shift during the 2000s using TRITON buoys and argo floats. J Clim 26(20):8126-8138

Hasson AEA, Delcroix T, Dussin R (2013) An assessment of the mixed layer salinity budget in the tropical Pacific Ocean. Observations and modelling (1990-2009). Ocean Dyn 63(2-3):179-194

Henley BJ, Gergis J, Karoly DJ, Power S, Kennedy J, Folland CK (2015) A tripole index for the interdecadal pacific oscillation. Clim Dyn 45(11-12):3077-3090

Hosoda S, Suga T, Shikama N, Mizuno K (2009) Global surface layer salinity change detected by argo and its implication for hydrological cycle intensification. J Oceanogr 65(4):579-586

Hu S, Sprintall J, Guan C, Hu D, Wang F, Lu X, Li S (2020) Observed triple mode of salinity variability in the thermocline of tropical Pacific Ocean. J Geophys Res Oceans 125:e2020JC016210

Ioualalen M, Henin C (2001) Thermohaline variability of the western tropical Pacific during 1995-1998: on the erosion/reconstitution of the fresh pool. J Geophys Res Oceans 106(C4):6869-6879

Johnson BK, Bryan FO, Grodsky SA, Carton JA (2016) Climatological annual cycle of the salinity budgets of the subtropical maxima. J Phys Oceanogr 46(10):2981-2994 
Kara AB, Rochford PA, Hurlburt HE (2000) An optimal definition for ocean mixed layer depth. J Geophys Res 105(C7):16803-16821

Li T, Liu P, Fu X, Wang B, Meehl GA (2006) Spatiotemporal structures and mechanisms of the tropospheric biennial oscillation in the Indo-Pacific warm ocean regions. J Clim 19(13):3070-3087

Li GC, Zhang YH, Xiao JG, Song XZ, Abraham J, Cheng LJ, Zhu J (2019) Examining the salinity change in the upper Pacific Ocean during the Argo period. Clim Dyn 53(9-10):6055-6074

Lorenz EN (1956) Empirical orthogonal functions and statistical weather prediction. Technical report, Statistical Forecast Project Report 1 Dept of Meteor MIT, pp 48

Maes C (2000) Salinity variability in the equatorial Pacific Ocean during the 1993-98 period. Geophys Res Lett 27(11):1659-1662

Maes C, Picaut J, Belamari S (2005) Importance of the salinity barrier layer for the buildup of El Nino. J Clim 18(1):104-118

Meehl GA, Arblaster JM, Fasullo JT, Hu AX, Trenberth KE (2011) Model-based evidence of deep-ocean heat uptake during surfacetemperature hiatus periods. Nat Clim Change 1(7):360-364

Nan F, Yu F, Xue HJ, Wang R, Si GC (2015) Ocean salinity changes in the northwest Pacific subtropical gyre: the quasi-decadal oscillation and the freshening trend. J Geophys Res Oceans 120(3):2179-2192

Qiu B, Chen S (2010) Interannual-to-decadal variability in the bifurcation of the north equatorial current off the Philippines. J Phys Oceanogr 40:2525-2538

Qu T, Gao S, Fukumori I, Fine RA, Lindstrom EJ (2009) Origin and pathway of equatorial $13^{\circ} \mathrm{C}$ water in the pacific identified by a simulated passive tracer and its adjoint. J Phys Oceanogr 39(8):1836-1853

Shi H, Du L, Xu D (2020) The robust salinity anomaly event during 2015-2017 in the tropical Pacific Ocean. Acta Oceanol Sin 42(3):47-58

Wang X, Chao Y (2004) Simulated sea surface salinity variability in the tropical Pacific. Geophys Res Lett 31:L02302

Xie SP, Hu K, Hafner J, Tokinaga H, Du Y, Huang G, Sampe T (2009) Indian Ocean capacitor effect on Indo-western Pacific climate during the summer following El Nino. J Clim 22:730-747
Yan YF, Xu DZ, Yu K, Qi YQ (2017) Propagation of the subsurface freshening water and its major source in the northwestern Pacific. J Geophys Res Oceans 122(8):6857-6871

Yan YF, Svendsen L, Wang CZ, Keenlyside N, Xu DZ (2019) A North-South contrast of subsurface salinity anomalies in the Northwestern Pacific from 2002 to 2013. J Geophys Res Oceans 124(3):1795-1806

Yu L, Weller RA (2007) Objectively analyzed air-sea heat fluxes for the global ice-free oceans (1981-2005). Bull Am Meteorol Soc 88(4):527-540

Zhang LL, Qu TD (2014) Low-frequency variability of South Pacific Tropical Water from Argo. Geophys Res Lett 41(7):2441-2446

Zhang Y, Du Y, Qu T (2016) A sea surface salinity dipole mode in the tropical Indian Ocean. Clim Dyn 47:2573-2585

Zhang Y, Du Y, Feng M (2018) Multiple time scale variability of the sea surface salinity dipole mode in the Tropical Indian Ocean. J Clim 31(1):283-296

Zhao M, Hendon HH, Yin Y, Alves O (2016) Variations of upper-ocean salinity associated with ENSO from PEODAS reanalyses. J Clim 29(6):2077-2094

Zheng F, Zhang RH (2012) Effects of interannual salinity variability and freshwater flux forcing on the development of the 2007/08 La Nina event diagnosed from Argo and satellite data. Dyn Atmos Oceans 57:45-57

Zheng F, Zhang RH (2015) Interannually varying salinity effects on ENSO in the tropical pacific: a diagnostic analysis from Argo. Ocean Dyn 65:691-705

Zhu J, Huang B, Zhang RH, Hu ZZ, Kumar A, Balmaseda MA et al (2014) Salinity anomaly as a trigger for ENSO events. Sci Rep 4:6821

Zuo H, Balmaseda MA, Tietsche S, Mogensen K, Mayer M (2019) The ECMWF operational ensemble reanalysis-analysis system for ocean and sea ice: a description of the system and assessment. Ocean Sci 15(3):779-808 